\title{
MICROVASCULAR HAEMODYNAMICS IN DIABETES
}

\author{
JOHN E. TOOKE \\ Exeter
}

Given the vast number of biochemical and cellular abnormalities described in diabetes mellitus it is little wonder that the microangiopathic complications of diabetes are commonly regarded as being multifactorial in origin. Proof that a particular abnormality is truly pathogenetic and not merely a paraphenomenon is seldom forthcoming and yet the development of preventive therapy may rely upon the identification and understanding of such prime-moving mechanisms. Rather than describe discrete biochemical and cellular abnormalities which may or may not be relevant, an alternative approach is to describe microvascular behaviour in more general terms to determine the evolution of functional disturbance with increasing duration of diabetes and cumulative exposure to elevated blood glucose levels - unarguably the two most important determinants. From the pattern of disturbance that evolves it should be possible to generate candidate mechanisms that fit the pathophysiological facts and thus are far more likely to be relevant.

The function of the microcirculation can broadly be described as the transport and exchange of nutrients and waste products between blood and tissue fluid. Accordingly an understanding of malfunction is likely to stem from knowledge of the determinants of exchange. The passage of a particular molecule across the capillary wall relies on many factors, most important of which are the size and charge of the molecule concerned, the permeability of the wall and the surface area available for exchange, and local haemodynamic factors (flow rate if the passage of the molecule is not diffusion-limited and the transcapillary pressure gradient for larger molecules that pass predominantly along with filtered water). In recent years a variety of specific techniques have become available which enable us to describe the changes in many of these important variables in diabetes mellitus. This article summarises the microvascular haemodynamic changes that are evident and which can be drawn together to generate a unifying hypothesis for the pathogenesis of diabetic microangiopathy.

Correspondence to: Professor J. E. Tooke, Diabetes Research Laboratories, Noy Scott House, Haldon View Terrace, Exeter EX2 5EQ, UK.

\section{HAEMODYNAMIC CHANGES IN INSULIN- DEPENDENT DIABETES}

Early insulin-dependent (type 1) diabetes is characterised by increased blood flow in many of the organs, including the eye, ${ }^{1}$ kidney $^{2}$ and peripheral tissues. ${ }^{3}$ Such elevation in perfusion appears to be related to glycaemic control and is largely reversed if normoglycaemia is achieved. If such an increase in flow is not accommodated by capillary recruitment and/or a fall in post-capillary resistance it is an inescapable conclusion that capillary pressure will rise. Studies of animal models of diabetes have confirmed glomerular capillary hypertension ${ }^{4}$ and more recently finger nailfold capillary hypertension has been demonstrated in human insulin-dependent diabetes. ${ }^{5}$

Early capillary hypertension is compatible with much of the other physiological data relating to insulin-dependent diabetes, including increased transcapillary escape rate of albumin, ${ }^{6}$ increased exchangeable sodium, reduced tissue oncotic pressure ${ }^{8}$ and a control-related increase in capillary filtration coefficient. ${ }^{6}$

In contrast to this early evidence of increased perfusion and capillary hypertension, insulin-dependent diabetes of long duration is characterised by limited flow reserve. For example, the pre-proliferative phase of diabetic retinopathy is a reaction to retinal ischaemia ${ }^{9}$ and renal plasma flow falls as creatinine begins to rise in diabetic nephropathy. ${ }^{10}$ In peripheral tissues there is a negative correlation between duration of diabetes and the maximum hyperaemic response to a variety of stimuli in both adults ${ }^{11}$ and children ${ }^{12}$ with insulin-dependent diabetes. Pharmacological studies suggest such changes are a consequence of impaired microvascular responsiveness rather than impaired generation of extrinsic mediators. ${ }^{13}$

How can these seemingly conflicting observations early hyperaemia and later underperfusion - be mutually compatible let alone linked in some way? The answer lies in the physiological appropriateness of the flow or pressure observed: Under basal conditions flow should be minimised; when stimulated, flow should increase appropriately - perhaps 30 - to 40 -fold in the skin, for example, in response to an injurious stimulus. It is thus quite poss- 
Table I. The haemodynamic hypothesis of diabetic microangiopathy

Early increased pressure and flow

Microvascular sclerosis

Limited flow reserve

ible to have a slight increase in resting flow and pressure yet at the same time a limitation of maximum vasodilatation. Several groups have linked these observations in mechanistic terms, suggesting that sustained increased pressure promotes an injury response by the microvessel wall (Table I). ${ }^{14-16}$ The resultant basement membrane thickening and arteriolar sclerosis (which are histological characteristics of diabetes) act to physically limit microvascular vasodilatation.

There is good evidence that capillary hydrostatic pressure is an important determinant of basement membrane thickening; for example, lower limb capillary basement membrane width increases the further below the heart the tissue sample is taken. ${ }^{17}$ Furthermore, the limitation in maximum hyperaemia observed has been correlated with the degree of sclerosis. ${ }^{18}$

\section{VALIDATION OF THE HAEMODYNAMIC HYPOTHESIS}

If a particular factor is to be regarded as a prime-moving mechanism in the genesis of the microvascular complications of diabetes it is a prerequisite that it meets certain criteria (Table II). Such criteria are derived from clinical observation and epidemiological studies:

1. Operative from early in diabetic life. To be truly 'prime-moving' (and not reactive to early damage) it is reasonable to propose that the mechanism should be evident from very early in diabetic life. Capillary hypertension has been observed within the first 2 years of insulinrdependent diabetes. ${ }^{5}$

2. Related to glycaemic control. In keeping with epidemiological evidence the mechanism should be related in some way to glycaemia. Capillary pressure is positively correlated with glycated haemoglobin concentration in the early years of diabetes ${ }^{5}$ but not in those patients with established severe complications, and falls with improvement in glycaemic control. ${ }^{19}$

3. Enhanced by passage through puberty. Microvascular complications develop more readily after puberty even when allowances are made for diabetes duration and glycaemic control. Passage through puberty in children with insulin-dependent diabetes is characterised by microvascular vasodilatation and lack of acquisition of enhanced posturally induced vasoconstriction as occurs in healthy children, ${ }^{20}$ both of which will tend to lead to capillary hypertension.

4. Enhanced by arterial hypertension. High arterial blood pressure is a risk factor for the development of microangiopathy. Capillary hypertension has been described in patients with essential hypertension. ${ }^{21}$ In healthy subjects a physiological rise in arterial blood pressure is not transmitted to the capillary bed, ${ }^{22}$ whereas in certain insulin-dependent diabetic patients such pressure 'autoregulation' is deficient.

5. More marked in highly susceptible individuals. Capillary hypertension is particularly marked in patients with incipient nephropathy who are known to be at higher risk of the other complications of diabetes. ${ }^{23}$

6. Absent in complication-free individuals. Patients who avoid microalbuminuria and diabetic retinopathy despite 20 years of diabetes have normal capillary pressure. $^{23}$

\section{THE ROLE OF BLOOD RHEOLOGICAL FACTORS}

The intrinsic resistance to flow possessed by blood may have an important bearing on microvascular haemodynamics and in vitro observation has defined changes in plasma and whole blood viscosity as well as in red and white cell deformability in diabetes. Although rheological abnormalities comply with certain of the key characteristics of a prime-moving mechanism, including presence from early in diabetes, relationship to pubertal status ${ }^{24}$ and absence in complication-free individuals, the significance of these observations is questionable in the light of a demonstrable increase in microvascular blood flow early in the disease. It is nonetheless possible that the rapid deformation of less flexible cells may enhance the tangential stress upon the microvascular wall, increasing the effects of capillary hypertension resultant upon precapillary vasodilatation.

\section{THE CELLULAR AND BIOCHEMICAL BASIS OF MICROVASCULAR HYPERAEMIA IN INSULIN-DEPENDENT DIABETES}

Ultimately the microvascular haemodynamic changes observed must reflect changes in cellular mechanisms consequent upon the diabetic state. Knowing the pattern of abnormality enables the generation of plausible hypotheses. The endothelial cell with its important local influence upon vascular tone may be affected directly by hyperglycaemia; alternatively its vasodilatory products may be enhanced by aminoacidaemia or quenched by accumulating advanced glycosylation end products; changes in calcium handling by the vascular smooth muscle cells may result from enhanced flux through the sorbitol pathway. ${ }^{25}$

In specific vascular beds local mechanisms may operate; indeed such variability would go some way to clarifying why individuals develop different specific complications at differing rates. In the renal vascular bed

Table II. Criteria for a prime-moving mechanism in the pathogenesis of diabetic microangiopathy

1. Operative from early in diabetic life

2. Related to glycaemic control

3 . Enhanced by passage through puberty

4. Enhanced by arterial hypertension

5. More marked in highly susceptible individuals

6. Absent in complication-free individuals 
intermediary metabolites, ${ }^{26}$ growth hormone and natriuretic factors ${ }^{27}$ have been thought to be important whereas in the retina the loss of pericyte control may be a primary event. $^{28}$. In the periphery subtle degrees of sympathetic denervation and the need to dissipate heat consequent upon the elevated metabolic rate associated with uncontrolled diabetes may be relevant. ${ }^{15}$

\section{PROSPECTS FOR REVERSAL AND PREVENTION}

If capillary hypertension is an important prime-moving mechanism in the genesis of diabetic microangiopathy then therapy may derive from a deeper understanding of the underlying biochemical process or more pragmatically by using pharmacological agents to alter vascular resistance in such a way as to neutralise the change. Preliminary experience in our own laboratory with low doses of an angiotension-converting enzyme inhibitor in normotensive microalbuminuric patients suggests that capillary hypertension may be reversed with this therapy.

Over and above pharmacological intervention, were it possible to identify very early in their diabetic life those susceptible individuals who exhibited particularly marked haemodynamic changes, the classical approach of good glycaemic control could be targeted at this population.

Key words: Diabetes mellitus, Haemodynamics, Microangiopathy, Microcirculation.

\section{REFERENCES}

1. Kohner EM, Hamilton AM, Saunders SJ, Sutcliffe BA, Bulpitt CJ. The retinal blood flow in diabetes. Diabetologia 1975;11:27-33.

2. Christiansen JS, Gammelgaard J, Tronier B, Svendsen PA, Parving H-H. Kidney function and size in diabetics, before and during initial insulin treatment. Kidney Int 1982;21: 683-8.

3. Gundersen HJG. Peripheral blood flow and metabolic control in juvenile diabetes. Diabetologia 1974;10:225-31.

4. Hostetter TH, Troy JL, Brenner BM. Glomerular hemodynamics in experimental diabetes mellitus. Kidney Int 1981;19:410-5.

5. Sandeman DD, Shore AC, Tooke JE. Capillary pressure in insulin dependent diabetics: the influence of disease duration, complications, and glycaemic control. N Engl J Med 1992;327:760-4.

6. Parving H-H, Noer I, Deckert T, Evrin P-E, et al. The effect of metabolic regulation on microvascular permeability to small and large molecules in short term juvenile diabetics. Diabetologia 1976;12:161-6.

7. O'Hare JA, Ferniss J, Twomey B, O'Sullivan JD. Essential hypertension and hypertension in diabetic patients without nephropathy. J Hypertens 1983;1(Suppl 2):200-3.

8. Fauchald P, Norseth J, Jervell J. Transcapillary colloid osmotic gradient, plasma volume and interstitial fluid volume in long-term type 1 (insulin-dependent) diabetes. Diabetologia 1985;28:269-73.

9. Bresnick GH, de Venecia G, Myers EL, Harris JA, Davis
MD. Retinal ischaemia in diabetic retinopathy. Arch Ophthalmol 1975;93:1300-10.

10. Mogensen CF, Christensen CK, Vittinghus E. The stages in diabetic renal disease. Diabetes 1983;32(Suppl 2):64-78.

11. Rayman G, Williams SA, Spencer PD, Smaje LH, Wise PH, Tooke JE. Impaired microvascular hyperaemic response to minor skin trauma in type I diabetes. BMJ 1986;292: 1295-8.

12. Shore AC, Price KJ, Sandeman DD, Green EM, Tripp JH, Tooke JE. Impaired microvascular hyperaemia in children with diabetes mellitus. Diabetic Med 1991;8:619-23.

13. Boolell M, Tooke JE. The skin hyperaemic response to local injection of substance $\mathrm{P}$ and capsaicin in diabetes mellitus. Diabetic Med 1990;7:898-901.

14. Parving H-H, Viberti GC, Keen H, Christiansen JS, Lassen NA. Haemodynamic factors in the genesis of diabetic microangiopathy. Metabolism 1983;32:943-9.

15. Tooke JE. Microvascular haemodynamics in diabetes mellitus. Clin Sci 1986;70:119-25.

16. Zatz R, Brenner BM. Pathogenesis of diabetic microangiopathy: the haemodynamic view. Am J Med 1986;80:443-53.

17. Vracko R. Skeletal muscle capillaries in diabetics: a quantitative analysis. Circulation 1970;41:271-83.

18. Kastrup J, Norgaard T, Parving H-H, et al. Impaired autoregulation of blood flow in subcutaneous tissue of long-term type I (insulin-dependent) diabetic patients with microangiopathy: an index of arteriolar dysfunction. Diabetologia 1985;28:711-7.

19. Sandeman DD, Flynn MD, Mawson DM, Saltzmann MB, Pym C, Shore AC, Tooke JE. Nailfold capillary pressure (CP) in type I (insulin-dependent) diabetes: relationship to acute metabolic control. Diabetologia 1991;34 (Suppl 2): P663, A166.

20. Shore AC, Price KJ, Sandeman DD, Tripp JH, Tooke JE. Abnormalities of the postural vasoconstriction response in diabetic children and adolescents. Diabetic Med 1990; 7 (Suppl 2):34A, P97.

21. Williams SA, MacGregor GA, Smaje LH, Wasserman SM, Tooke JE. Capillary hypertension and abnormal pressure dynamics in patients with essential hypertension. Clin Sci 1990;79:5-8.

22. Shore AC, Sandeman DD, Tooke JE. The response of human nailfold capillary pressure to an increase in brachial artery blood pressure. In: Fifth World Congress for Microcirculation, Louisville, USA, 1991.

23. Shore AC, Jaap AJ, Tooke JE. Capillary pressure in type 1 diabetic patients of long disease duration with and without microangiopathy. Diabetic Med 1992;9 (Suppl 2):S11, A4.

24. McMillan DE, Utterback NG, Walff CW. Blood viscosity in young and old diabetics. Pediatr Adolesc Endocrinol 1981; 9:8-14.

25. Larkins RG, Dunlop ME.The link between hyperglycaemia and diabetic nephropathy. Diabetologia 1992;35:499-504.

26. Trevisan R, Nosadini R, Fioretto P, Velussi M, et al. Metabolic control of kidney haemodynamics in normal and insulin-dependent diabetic subjects. Diabetes 1987;36: 1973-81.

27. Ortola FV, Ballerman BJ, Anderson S, Mendez RE, et al. Elevated plasma atrial natriuretic peptide levels in diabetic rats: potential mediator of hyperfiltration. J Clin Invest 1987;80:670-4.

28. Merimee TJ. Diabetic retinopathy: a synthesis of perspectives. N Engl J Med 1990;322:978-82. 